\title{
Triamcinolone and Prednisolone Affect Contractile Properties and Histopathology of Rat Diaphragm Differently
}

\author{
P. N. Richard Dekhuijzen, Ghislaine Gayan-Ramirez, Vera de Bock, Rene Dom, and Marc Decramer \\ Respiratory Muscle Research Unit, Laboratory of Pneumology and Respiratory Division, and Department of Neuropathology, \\ University Hospital, Katholieke Universiteit Leuven, B-3000 Leuven, Belgium
}

\begin{abstract}
Diaphragm atrophy and weakness occur after administration of massive doses of corticosteroids for short periods. In the present study the effects of prolonged administration of moderate doses of fluorinated and nonfluorinated steroids were investigated on contractile properties and histopathology of rat diaphragm. 60 rats received saline, $1.0 \mathrm{mg} / \mathrm{kg}$ triamcinolone, or 1.25 or $5 \mathrm{mg} / \mathrm{kg}$ i.m. prednisolone daily for 4 wk. Respiratory and peripheral muscle mass increased similarly in control and both prednisolone groups, whereas triamcinolone caused severe muscle wasting. Maximal tetanic tension averaged $2.23 \pm 0.54 \mathrm{~kg} / \mathrm{cm}^{2}$ (SD) in the control group. An increased number of diaphragmatic bundles in the $5-\mathrm{mg} / \mathrm{kg}$ prednisolone group generated maximal tetanic tensions $<2.0 \mathrm{~kg} / \mathrm{cm}^{2}(P$ $<0.05)$. In addition, fatigability during the force-frequency protocol was most pronounced in this group $(P<0.05)$. In contrast, triamcinolone caused a prolonged half-relaxation time and a leftward shift of the force-frequency curve $(P<0.05)$. Histological examination of the diaphragm showed a normal pattern in the control and $1.25-\mathrm{mg} / \mathrm{kg}$ prednisolone group. Myogenic changes, however, were found in the 5-mg/ $\mathrm{kg}$ prednisolone group and, more pronounced, in the triamcinolone group. Selective type IIb fiber atrophy was found in the latter group, but not in the prednisolone groups. In conclusion, triamcinolone induced type IIb fiber atrophy, resulting in reduced respiratory muscle strength and a leftward shift of the forcefrequency curve. In contrast, $5 \mathrm{mg} / \mathrm{kg}$ prednisolone caused alterations in diaphragmatic contractile properties and histological changes without fiber atrophy. (J. Clin. Invest. 1993. 92:1534-1542.) Key words: corticosteroids • myopathy $\bullet$ atrophy $\bullet$ respiratory muscles $\bullet$ chest wall mechanics
\end{abstract}

\section{Introduction}

Myopathy and atrophy of peripheral skeletal muscles are wellknown side effects of treatment with corticosteroids, especially with fluorinated steroids (1-5). Recent animal studies have demonstrated that the diaphragm may be involved (6-12), but the extent to which the human diaphragm may be affected is still unclear. 2-wk treatment with $40 \mathrm{mg}$ prednisolone daily did not affect maximal inspiratory mouth pressure or respiratory

Address correspondence and reprint requests to Marc Decramer, Respiratory Division, University Hospital, Weligerveld 1, B-3212 Pellenberg, Belgium.

Received for publication 13 July 1992 and in revised form 16 February 1993.

J. Clin. Invest.

(c) The American Society for Clinical Investigation, Inc. 0021-9738/93/09/1534/09 \$2.00

Volume 92, September 1993, 1534-1542 muscle endurance in normal subjects (13). In patients with collagen vascular disorders or with asthma and chronic obstructive pulmonary disease (COPD), ${ }^{1}$ however, steroid treatment may reduce respiratory muscle function $(14,15)$.

Animal studies have shown that diaphragmatic mass $(6,8$, $11)$, function $(8,12)$, fiber type dimensions $(7,10,12)$, and biochemical characteristics $(9,12)$ are affected by the administration of steroids. In the majority of these studies, however, animals were treated with massive doses of steroids during short periods, likely to produce acute myopathy and atrophy rather than chronic myopathy $(6-8,10-12,16)$. The latter disorder is probably more relevant to clinical medicine (16).

The present study was, therefore, designed to investigate the effects of prolonged administration of a fluorinated (triamcinolone) and a nonfluorinated steroid (prednisolone) in moderate doses, likely to produce chronic myopathy, on contractile properties and histopathology of rat diaphragm.

\section{Methods}

\section{Study design, animals, and treatment}

60 adult male Wistar rats, aged $14 \mathrm{wk}$, weighing $350-400 \mathrm{~g}$, were randomized in quadruplets, into one of four treatment groups: control (C), saline, $0.05 \mathrm{ml} / \mathrm{d}$ i.m.; low dose prednisolone (LD), $1.25 \mathrm{mg} / \mathrm{kg}$ per d i.m.; high dose prednisolone (HD), $5 \mathrm{mg} / \mathrm{kg}$ per d i.m.; or triamcinolone-diacetate (TR), $1 \mathrm{mg} / \mathrm{kg}$ per $\mathrm{d}$ i.m. Dilution of medication was performed such that with each injection all animals received a similar volume $(0.05 \mathrm{ml})$. During $4 \mathrm{wk}$ the animals were injected daily in the left hindlimb. They were fed ad libitum and weighed twice weekly. After the treatment period, contractile properties, histological, and histochemical characteristics of the diaphragm were examined.

\section{Contractile properties}

$24 \mathrm{~h}$ after the last injection, rats were anesthetized with sodium pentobarbital (Nembutal, $60 \mathrm{mg} / \mathrm{kg}$ i.p.). Animals were tracheotomized and a tracheal cannula (polyethylene tubing PE-200) was inserted. They were mechanically ventilated with an $\mathrm{O}_{2}$-enriched gas mixture (pump respirator; Harvard Apparatus, South Natick, MA; tidal volume $5 \mathrm{ml}$, respiratory frequency $40 / \mathrm{min}$ ).

The diaphragm was quickly removed through a laparotomy and was immediately immersed in a cooled, oxygenated Krebs solution containing (mmol/liter): $137 \mathrm{NaCl}, 4 \mathrm{KCl}, 2 \mathrm{CaCl}_{2}, 1 \mathrm{MgCl}_{2}, 1$ $\mathrm{KH}_{2} \mathrm{PO}_{4}, 12 \mathrm{NaHCO}_{3}$, and 6.5 glucose. The distribution of the three fiber types in rat diaphragm is similar in all regions, except for the crural region, which contains significantly more type IIb fibers (17). Regional differences in cross-sectional area (CSA) in rat diaphragm fibers have not been described to the best of our knowledge. To avoid any variations as much as possible, two small rectangular bundles from

1. Abbreviations used in this paper: $\mathrm{C}$, control; $\mathrm{COPD}$, chronic obstructive pulmonary disease; CSA, cross-sectional area; HD, high dose prednisolone; LD, low dose prednisolone; Lo, optimal length; Po, maximal tetanic tension; Pt, maximal twitch tension; $1 / 2 \mathrm{RT}$, half relaxation time; TPT, time to peak tension; TR, triamcinolone-diacetate. 
the middle part of the lateral costal region of each hemidiaphragm were obtained by careful dissection parallel to the long axis of the fibers. Silk sutures were firmly tied to both ends of the bundle to serve as anchoring points.

Each bundle was then placed within the external chamber of a jacketed tissue bath containing Krebs solution, maintained at $37^{\circ} \mathrm{C}$, and perfused with a $95 \% \mathrm{O}_{2}$ and $5 \% \mathrm{CO}_{2}$ mixture. One end of the bundle was tied to a rigid support, while the other was fastened to an isometric force transducer mounted to a micrometer. The muscle was placed in between two large platinum stimulating electrodes.

After a 15-min thermoequilibration period, the bundles were placed at their optimal length (Lo), defined as the length at which peak twitch force was obtained. Stimulations were delivered through a stimulator (model 50-5016; Harvard Apparatus, Edenbridge, Kent, U.K.) connected in series to a power amplifier from power one model HS244.8 (R. J. Evans, University of Virginia). Stimuli were applied with a pulse duration of $0.2 \mathrm{~ms}$ and a train duration of $250 \mathrm{~ms}$. Maximum twitch tension was achieved at $\pm 34 \mathrm{~V}$. The voltage was then increased by $20 \%$ to ensure supramaximal stimulation. This voltage was subsequently used during all stimulations. Isometric force was measured by means of a force transducer (Maywood Ltd., Hampshire, U.K.). The signal was amplified and recorded on a hot pen recorder (W \& W Electronics, Basel, Switzerland). Measurements were directly made from the recorder tracings.

The following measurements were performed:

Twitch characteristics. Two twitches were recorded at Lo to determine maximal twitch tension (Pt), time to peak tension (TPT), and half relaxation time $(1 / 2 \mathrm{RT})$. Average values were used for further analysis.

Maximal tetanic tension. Bundles were stimulated twice tetanically at $160 \mathrm{~Hz}$, during $250 \mathrm{~ms}$ to obtain a clear plateau in force generation. Maximal tetanic tension (Po) was recorded as the maximal tension elicited at $160 \mathrm{~Hz}$, since previous studies have shown that at $37^{\circ} \mathrm{C}$ maximal force generation is achieved at this stimulus frequency in rat diaphragm $(18,19)$. Values were expressed both in absolute values $(\mathrm{kg})$ and corrected for CSA $(6,11)$ (see below).

Force-frequency curve. Bundles were stimulated at the following frequencies: $25,160,50,160,80,160,120$, and $160 \mathrm{~Hz}$. Each stimulus was separated by a 2 -min interval.

Fatigue properties. Fatigability was assessed in two different ways. First, force output at $160 \mathrm{~Hz}$ after each stimulus frequency during the force-frequency curve was measured. Second, bundles were fatigued by means of 330-ms stimulations repeated at $25 \mathrm{~Hz}$ and applied every second during 5 min (modified after Burke et al., [20]).

After these measurements, each muscle bundle was removed from the bath and its length, thickness, and width were measured at Lo. The bundle was blotted dry and weighed. CSA was calculated by dividing weight by specific density (1.056) and muscle length. Twitch and tetanic forces were expressed per unit CSA. Twitch/tetanus ratio (Pt/ Po) was calculated for each muscle bundle.

Finally, the remaining diaphragm tissue was trimmed, blotted, and weighed. Parasternal muscles (including sternum and chondral parts of the ribs), right medial scalene muscle, and the medial gastrocnemius from the right hindlimb were dissected, trimmed, blotted, and weighed.

\section{Histological and histochemical procedures}

Muscle strips obtained from the costal region of the diaphragm were put into tissue glue ( Tissue-Tek, Elkhart, IN) on a cork holder, with the muscle fibers oriented perpendicularly to the surface of the cork. Proper orientation of the bundles was controlled by using magnifying glasses during this procedure. Subsequently, these specimens were quickly frozen in isopentane cooled with liquid $\mathrm{N}_{2}$. Serial cross sections were cut at $10-\mu \mathrm{m}$ thickness with a cryostat kept at $-20^{\circ} \mathrm{C}$, parallel to the cork. Two sections of each diaphragm were taken for routine hematoxylin and eosin staining.

The other serial sections were stained for myofibrillar adenosine triphosphatase after alkaline ( $\mathrm{pH} \mathrm{9.3)} \mathrm{and} \mathrm{acid} \mathrm{(} \mathrm{pH} \mathrm{4.3)} \mathrm{preincuba-}$ tion. Muscle fibers were classified as type I ( slow-twitch), type IIa (fast-

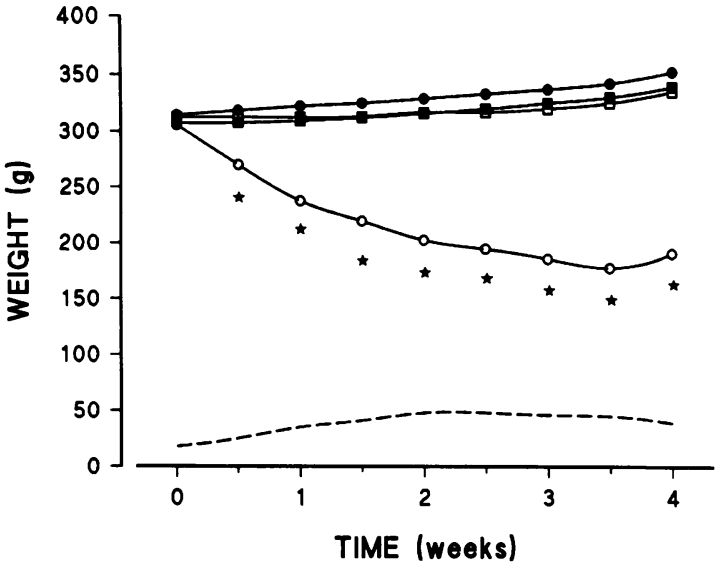

Figure 1. Weight vs. time during the 4-wk treatment period. Closed circles, control; closed squares, LD prednisolone; open squares, HD prednisolone; open circles, triamcinolone; dashed line, pooled SD. ${ }^{*} P$ $<0.01$ compared with C, LD, and HD.

twitch oxidative), or type IIb (fast-twitch glycolytic) fibers (21). Slides preincubated at $\mathrm{pH} 4.3$ offered the best separation of different fiber types and were consequently used for further analysis.

Morphometric examination was carried out with a microscope (E. Leitz Inc., Wetzlar, Germany), at $25 \times$ magnification, connected to a digitizing board (model 2207; Numonics Corp., Montgomeryville, PA). Areas in which fiber orientation was not transverse to the long axis were not analyzed. Fiber diameters were determined by measuring the maximum diameter perpendicular to the long axis. Boundaries of individual muscle fibers were delineated, and fiber CSAs were determined from the number of pixels within the outlined fiber. A shape factor was calculated as $\left(4 \times \pi \times \mathrm{CSA}^{2}\right) /$ perimeter $^{2}$. At least 250 fibers of each diaphragm were used to calculate mean diameter, shape factor, and CSA of all fiber types.

\section{Data analysis}

Two diaphragm bundles were obtained from each animal and were subsequently used for statistical analysis as independent cases. Data from the different treatment groups were compared, using two-way analysis of variance. Differences between means were assessed using Duncan's multiple range test. A chi-square likelihood ratio test was used to detect differences in the distribution of maximal tetanic tensions between the four treatment groups. Statistical significance was set at $P<0.05$. All analyses were performed using the SPSS $/ \mathrm{PC}+$ package (22). Means $\pm S D$ are represented in text, tables, and figures unless otherwise specified.

\section{Results}

Body and muscle weight

Body weight at the start of the study was not different between the four groups (Fig. 1). In C, LD, and HD groups weight

Table I. Muscle Masses*

\begin{tabular}{lcccc}
\hline \multicolumn{1}{c}{ Treatment } & Diaphragm & Parasternals & Scalenus & Gastrocnemius \\
\hline $\begin{array}{l}\text { Control } \\
\text { Prednisolone }\end{array}$ & $380(45)$ & $2,772(309)$ & $460(90)$ & $634(101)$ \\
$\quad 1.25 \mathrm{mg} / \mathrm{kg}$ & $365(88)$ & $2,892(377)$ & $445(78)$ & $600(100)$ \\
$\quad 5 \mathrm{mg} / \mathrm{kg}$ & $354(55)$ & $2,808(288)$ & $451(110)$ & $616(153)$ \\
$\begin{array}{l}\text { Triamcinolone } \\
\quad 1 \mathrm{mg} / \mathrm{kg}\end{array}$ & $230(50)^{\ddagger}$ & $1,654(291)^{\ddagger}$ & $165(29)^{\ddagger}$ & $228(65)^{\ddagger}$ \\
\hline
\end{tabular}

Mean \pm SD. ${ }^{*}$ Values are expressed in $\mathrm{mg} .{ }^{\ddagger} P<0.001$ compared with $\mathrm{C}, \mathrm{LD}$, and $\mathrm{HD}$. 
Table II. Diaphragm Bundle Dimensions

\begin{tabular}{lcccc}
\hline \multicolumn{1}{c}{ Treatment } & Length & Thickness & Width & Weight \\
\hline & & $m m$ & $m g$ \\
Control & $18.0(2.2)$ & $0.49(0.11)$ & $1.58(0.26)$ & $22.4(4.8)$ \\
Prednisolone & & & & \\
$\quad 1.25 \mathrm{mg} / \mathrm{kg}$ & $17.9(1.5)$ & $0.52(0.13)$ & $1.56(0.26)$ & $21.4(3.6)$ \\
$\quad 5 \mathrm{mg} / \mathrm{kg}$ & $17.4(1.7)$ & $0.49(0.11)$ & $1.56(0.18)$ & $22.1(4.4)$ \\
$\begin{array}{c}\text { Triamcinolone } \\
1 \mathrm{mg} / \mathrm{kg}\end{array}$ & $16.4(2.0)$ & $0.41(0.10)^{*}$ & $1.25(0.13)^{*}$ & $11.8(2.2)^{*}$ \\
\hline
\end{tabular}

Mean $\pm \mathrm{SD}$. ${ }^{*} P<0.05$ compared with $\mathrm{C}, \mathrm{LD}$, and $\mathrm{HD}$.

increased during the treatment period, whereas it severely decreased in the TR group $(P<0.01)$. In the latter group seven animals $(47 \%)$ died after $20 \pm 5 \mathrm{~d}$ presumably because of severe muscle wasting, whereas in the other three groups no mortality was observed.

Masses of respiratory and peripheral muscles are shown in Table I. All muscle masses were clearly reduced in the TR group. In three TR-treated animals the medial scalene muscle completely disappeared at both sides. For all muscles studied, weight varied proportionally to body weight.

\section{Diaphragm bundle dimensions}

Bundle dimensions were similar in C, LD, and HD groups (Table II). In the TR group thickness and width were signifcantly smaller, resulting in a lower bundle weight $(P<0.05)$.

\section{Diaphragmatic contractile properties}

Twitch characteristics. Pt tended to decrease in prednisolonetreated animals and to increase in the triamcinolone-treated animals, but these differences did not reach statistical significance (Table III). Passive tensions at which maximal twitch tension was measured were similar in all groups (means $\pm \mathrm{SD}$ ): C, $0.84 \pm 0.47 \mathrm{~g} ; \mathrm{LD}, 0.69 \pm 0.49 \mathrm{~g} ; \mathrm{HD}, 0.67 \pm 0.42 \mathrm{~g}$; TR, $0.74 \pm 0.62 \mathrm{~g}$. TPT in the HD group was shorter than in $\mathrm{C}$ and TR groups $(P<0.05)$. In the TR group, $1 / 2 \mathrm{RT}$ was signifcantly prolonged compared with the other three groups $(P$ $<0.001$ ).

Maximal tetanic tension. Po expressed in kilograms was significantly lower in the TR group compared with the other groups (Table III). When normalized for CSA, Po was not significantly different between the four groups (Table III). However, when the values were divided in three classes (Po $<1.5,1.5<\mathrm{Po}<2.0$, and $\mathrm{Po}>2.0 \mathrm{~kg} / \mathrm{cm}^{2}$ ), more bundles

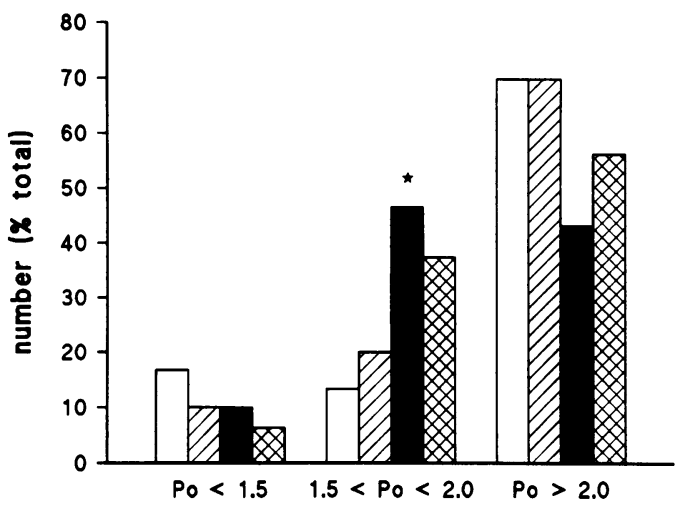

Figure 2. Maximal tetanic tension ( $\mathrm{Po}$, expressed in $\mathrm{kg} / \mathrm{cm}^{2}$ ) divided into three subgroups. Open bars, control; hatched bars, LD prednisolone; solid bars, HD prednisolone; crosshatched bars, triamcinolone. ${ }^{*} P<0.05$ compared with $C$.

generated tetanic tensions between 1.5 and $2.0 \mathrm{~kg} / \mathrm{cm}^{2}$ in the HD group (Fig. 2, chi-square $=9.472, P<0.05$ ). The distribution of bundles with Po values $<1.5 \mathrm{~kg} / \mathrm{cm}^{2}$ was not different between the four groups, indicating that dissection injury was probably evenly distributed among the treatment groups. $\mathrm{Pt} /$ Po in prednisolone-treated animals was significantly lower than in the TR group (Table III, $P<0.001$ ).

Force-frequency curve. The response of diaphragm strips to increasing stimulus frequencies is shown in Fig. 3. When expressed in absolute values (Fig. 3, top), stress developed at 25 $\mathrm{Hz}$ was higher in the TR group compared with $\mathrm{C}, \mathrm{LD}$, and HD groups $(P<0.05)$. Force generation tended to decrease with increasing prednisolone dose, but the differences did not reach statistical significance. When expressed as a percentage of the $160-\mathrm{Hz}$ stimulations before and after each stimulus frequency, this tendency was no longer present, although the force generation at $25 \mathrm{~Hz}$ was still greater in the TR group (Fig. 3, bottom).

\section{Fatigue properties}

Decline in maximal tetanic tension during force-frequency protocol. In all groups force generated at $160 \mathrm{~Hz}$ during the forcefrequency stimulation procedure decreased significantly. In the C, LD, HD, and TR groups the percentage decreases compared with initial Po were $7.7 \pm 1.7,10.1 \pm 2.2,14.2 \pm 2.5$, and $6.2 \pm 2.2$ (mean $\pm \mathrm{SE}$ ), respectively. Thus, the TR group showed the smallest decline, whereas the HD group exhibited the most pronounced decrease $(P<0.05$ compared with the other groups). As a consequence, fatigue during the force-frequency

Table III. Diaphragmatic Contractile Properties

\begin{tabular}{|c|c|c|c|c|c|c|}
\hline Treatment & $\mathrm{Pt}$ & TPT & $1 / 2 \mathrm{RT}$ & Po & Po & $\mathrm{Pt} / \mathrm{Po}$ \\
\hline & $\mathrm{kg} / \mathrm{cm}^{2}$ & & & $k g$ & $\mathrm{~kg} / \mathrm{cm}^{2}$ & \\
\hline Control & $0.640(0.208)$ & $23(2)$ & $18(4)$ & $0.026(0.008)$ & $2.23(0.54)$ & $0.28(0.04)$ \\
\hline \multicolumn{7}{|l|}{ Prednisolone } \\
\hline $1.25 \mathrm{mg} / \mathrm{kg}$ & $0.593(0.191)$ & $22(3)$ & $19(3)$ & $0.024(0.007)$ & $2.16(0.52)$ & $0.27(0.04)$ \\
\hline $5 \mathrm{mg} / \mathrm{kg}$ & $0.580(0.243)$ & $21(3)^{*}$ & $19(3)$ & $0.025(0.006)$ & $2.17(0.69)$ & $0.26(0.05)$ \\
\hline \multicolumn{7}{|l|}{ Triamcinolone } \\
\hline $1 \mathrm{mg} / \mathrm{kg}$ & $0.693(0.242)$ & $23(5)$ & $26(7)^{\ddagger}$ & $0.015(0.004)^{\ddagger}$ & $2.25(0.64)$ & $0.31(0.04)^{8}$ \\
\hline
\end{tabular}

Mean \pm SD. ${ }^{*} P<0.05$ compared with $\mathrm{C}$ and TR. ${ }^{\ddagger} P<0.001$ compared with $\mathrm{C}, \mathrm{LD}$, and HD. ${ }^{\S} P<0.001$ compared with $\mathrm{LD}$ and $\mathrm{HD}$. 

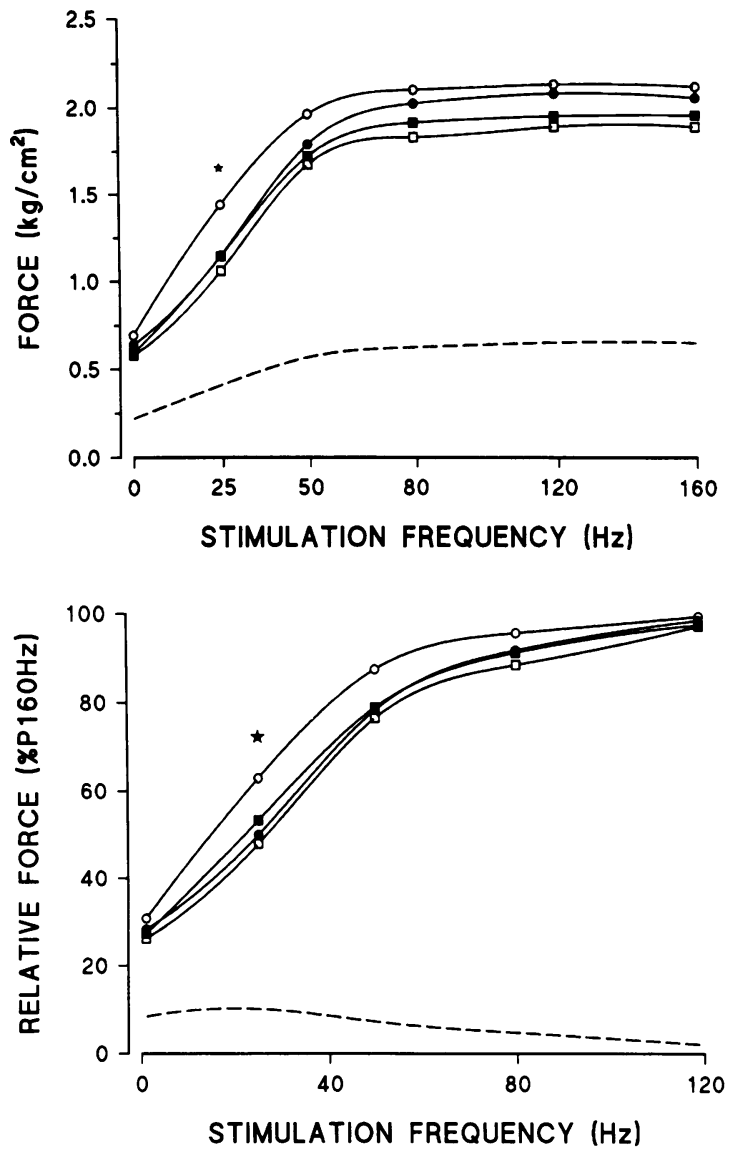

Figure 3. (Top) Force-frequency curve, expressed in $\mathrm{kg} / \mathrm{cm}^{2} .{ }^{*} P$ $<0.05$ compared with C, LD, and HD. (Bottom) Force-frequency curve, expressed as percentage of $160-\mathrm{Hz}$ stimulations. Closed circles, control; closed squares, LD prednisolone; open squares, HD prednisolone; open circles, triamcinolone; dashed line, pooled SD.

curve was smallest in the TR group and greatest in the HD group.

Fatigue run. During the low-frequency fatigue run, stress generation in the TR group was higher than in the other groups (Fig. $4, P<0.05$ ). The same pattern was observed when values were expressed as percentage of initial stresses.

\section{Histopathology}

Histological examination of hemotoxylin and eosin-stained slides showed a normal muscular pattern in both $\mathrm{C}$ and LD groups. In the HD group, however, myogenic changes were noticed, with greater than normal variation of the diameter of all fiber types, scattered necrotic or atrophic fibers, excess of nuclei, and increased amount of connective tissue (Fig. 5, bottom left). No atrophy of type IIb fibers was observed. Even more pronounced pathological changes were found in TR group, with variations in diameters of all muscle fiber types, atrophy of IIb fibers (Fig. 5, bottom right), increase in number of nuclei, and an increased amount of connective tissue. More necrotic fibers were present than in the HD group.

\section{Morphometry}

Fiber type distribution was not changed by different treatments. In general, diaphragm consisted of $40 \%$ type I fibers, $30 \%$ type IIa fibers, and 30\% type IIb fibers (Table IV). Muscle fiber dimensions were affected differently according to the type

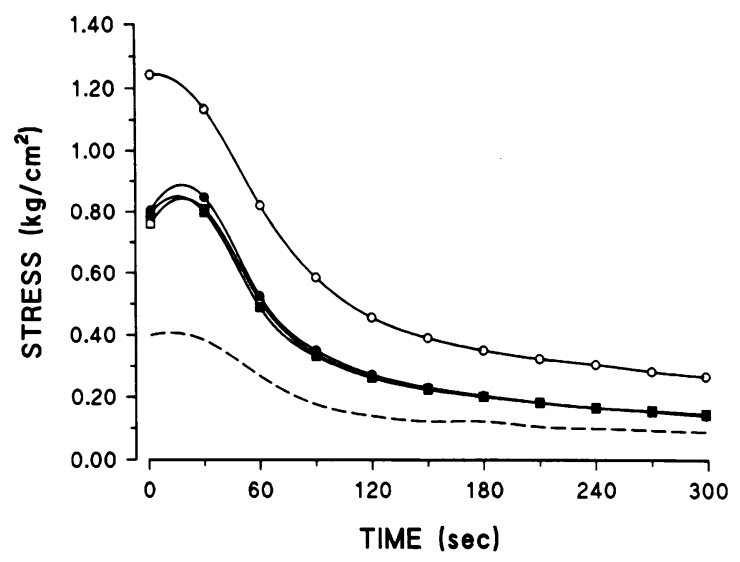

Figure 4. Fatigue curve, expressed in $\mathrm{kg} / \mathrm{cm}^{2}$. Closed circles, control; closed squares, LD prednisolone; open squares, HD prednisolone; open circles, triamcinolone; dashed line, pooled SD.

of steroid administered. Mean diameters of type I, IIa, and IIb fibers were similar in C, LD (Fig. 5, top), and HD groups. In the TR group, however, the diameter of type IIb fiber was significantly reduced (Fig. 5, bottom right and Fig. 6, top, $P<0.05$ ), whereas type I and IIa diameters were unaffected. CSA of these type IIb fibers in the TR group was decreased even more clearly (Fig. 6, bottom, $P<0.001$ ). Type I and IIa CSA were similar in the four treatment groups.

No significant differences were observed in shape factor between the four groups. The mean values were $0.77,0.75$, and 0.77 for the type I, IIa, and IIb fibers, respectively. For all groups and all fibers studied shape factor ranged from 0.69 to 0.82 .

\section{Discussion}

The present data show that triamcinolone and prednisolone affect diaphragm function in a clearly different way. Triamcinolone treatment caused selective type IIb fiber atrophy of the diaphragm. Type IIb fiber atrophy was further confirmed by the observed alterations in contractile properties. Indeed, the prolonged $1 / 2 \mathrm{RT}$, higher force generation at low stimulus frequencies, and the relative resistance to fatigue during the forcefrequency protocol all are consistent with type Ilb atrophy (7).

More subtle changes were noticed in the prednisolonetreated animals. Relatively more diaphragmatic bundles generated tetanic tensions $<2.0 \mathrm{~kg} / \mathrm{cm}^{2}$ compared with control. Moreover, a significantly greater decline in force during the force-frequency protocol was present in the HD group. These changes in contractile and fatigue properties are compatible with the pathological changes in the HD prednisolone group. In contrast to the response to triamcinolone, no (selective) fiber type atrophy occurred with HD prednisolone. The alterations in the $5-\mathrm{mg} / \mathrm{kg}$ prednisolone diaphragms were typically myogenic in origin (21). Abnormalities suggesting neurogenic changes such as generalized fiber atrophy and small group and large group atrophy (21) were not found in these steroidtreated diaphragms.

Bundle dimensions themselves may affect contractile properties (23). The changes in contractile properties in the TRtreated diaphragms could potentially be due to the fact that the bundles were smaller in this group. Segal and Faulkner (23) studied the influence of muscle thickness and incubation tem- 

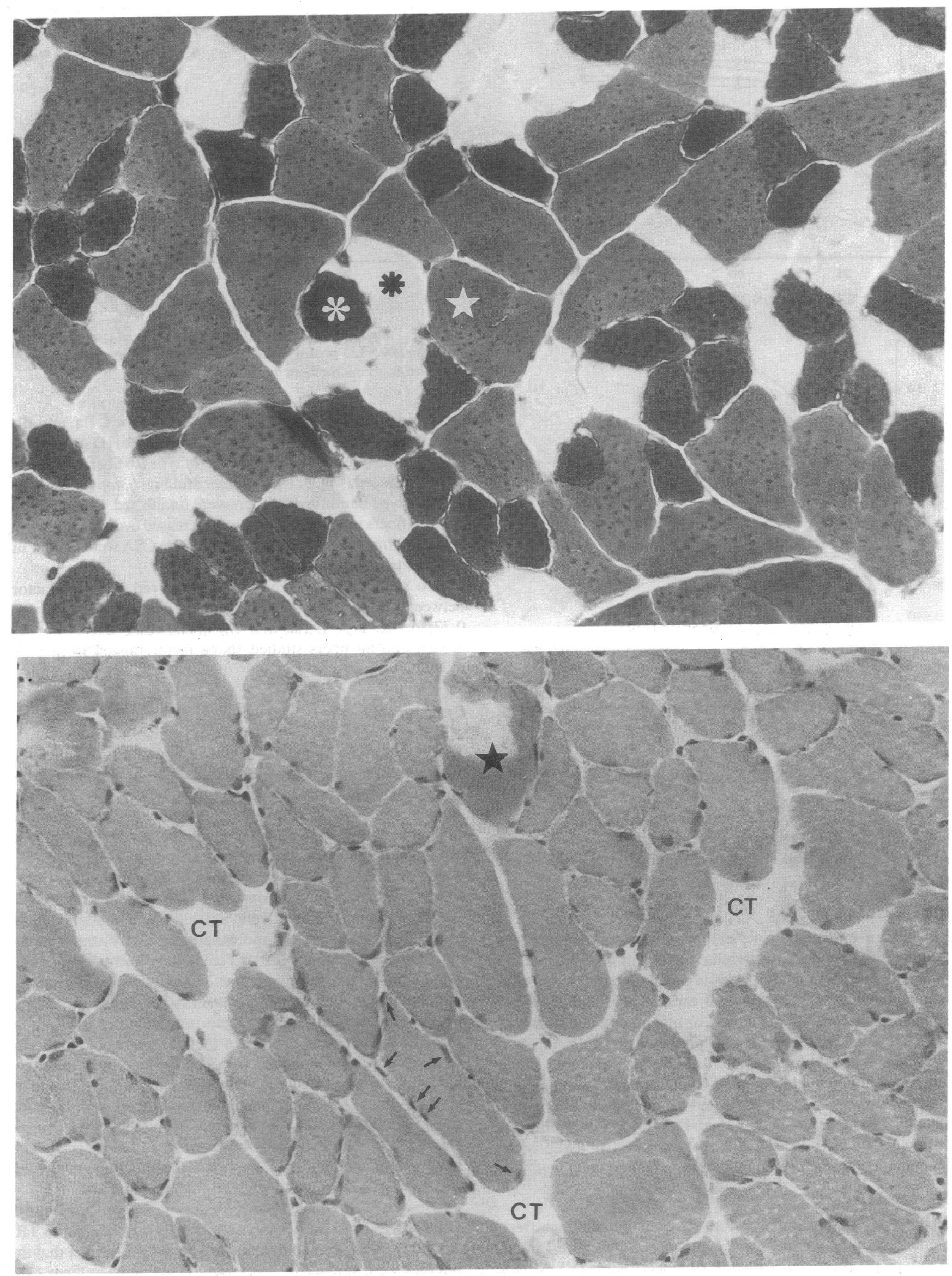

Fig.5 

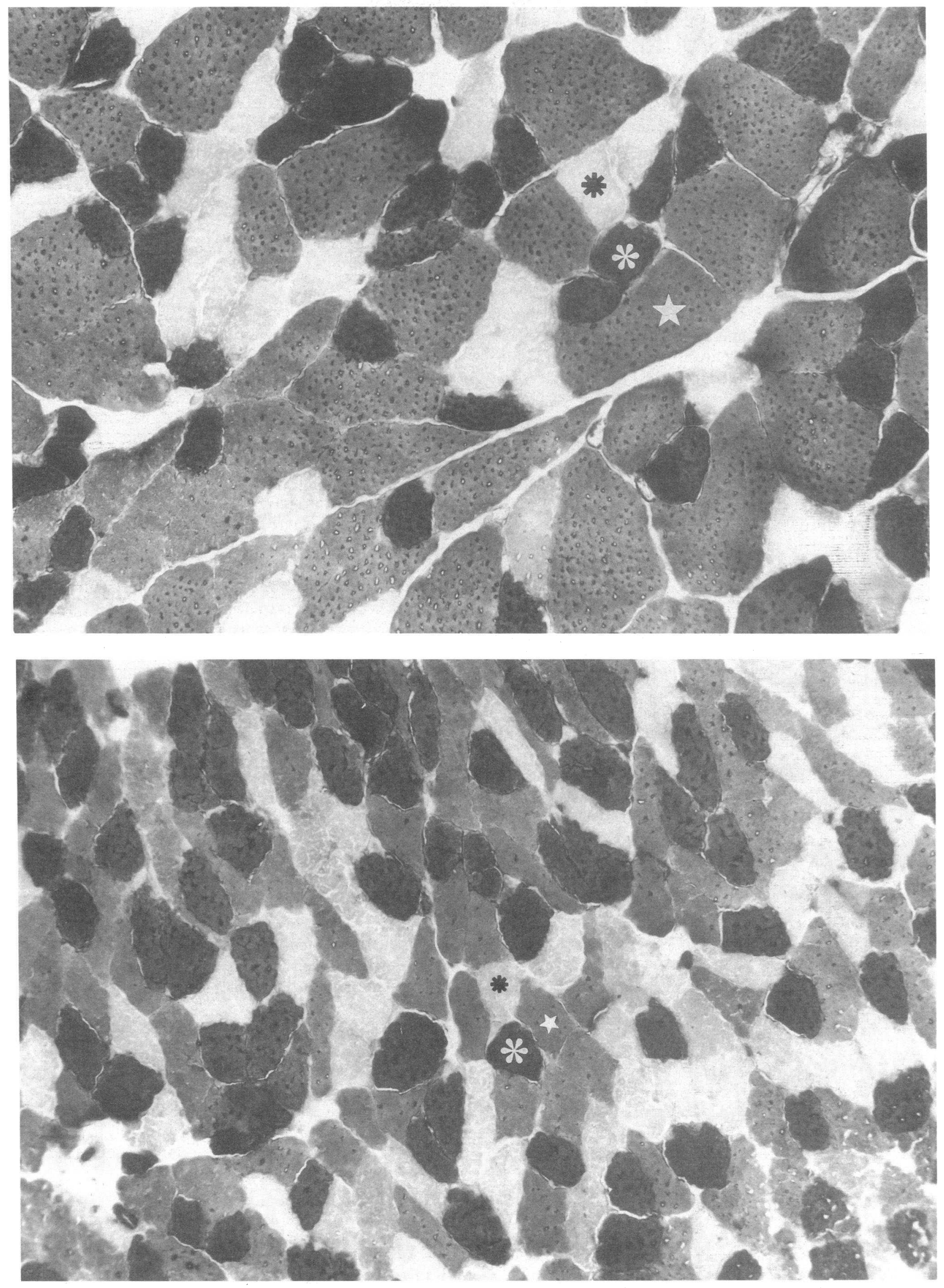

Fig.5 
perature on the contractile properties of rat skeletal muscles. They showed that the critical radius for $\mathrm{O}_{2}$ diffusion (i.e., the distance into a muscle at which $\mathrm{O}_{2}$ tension declined to zero) was $\pm 0.6 \mathrm{~mm}$ at $37^{\circ} \mathrm{C}$. This is clearly above the radius of the bundles in our study, which varied from 0.20 (triamcinolone group) to $0.26 \mathrm{~mm}$ (1.25-mg/ $\mathrm{kg}$ prednisolone group). Therefore, it seems unlikely that differences in bundle dimensions and consequent differences in oxygen diffusion would account for the observed changes in contractile properties.

Another important issue is whether the use of sodium pentobarbital (Nembutal) may have affected contractile properties in vitro. The direct effects of pentobarbital on medial soleus and medial extensor digitorum longus in mice were described by Taylor et al. (24). In their study pentobarbital was added to the muscle bath in concentrations of $0.1,0.2,0.4$, and $0.8 \mathrm{mM}$. Only the highest concentration had small effects on Po and twitch characteristics. In the study by Warner et al. (25) administration of $25 \mathrm{mg} / \mathrm{kg}$ i.v. in dogs resulted in plasma levels of $\sim 25 \mu \mathrm{g} / \mathrm{ml}$ or $0.1 \mathrm{mM}$. In the present study $60 \mathrm{mg} / \mathrm{kg}$ i.p. was administered, but no serum levels were measured. Even assuming perfect reabsorption, which is unlikely in view of the intraperitoneal route of administration and the short duration between induction of anesthesia and removal of the diaphragm, and similar kinetics as in dogs, a serum level of $0.24 \mathrm{mM}$ would have been obtained. This is clearly below the concentration at which effects were obtained by Taylor et al. (24). This suggests that the effects of pentobarbital in the present study, if present, must have been negligible.

Our data are in line with recent investigations, indicating that histochemical and contractile properties of the diaphragm are affected by corticosteroids ( $6-12)$. In the study by Moore et al. (6), treatment with cortisone acetate $(100 \mathrm{mg} / \mathrm{kg}$ per d i.m.) during $10 \mathrm{~d}$ resulted in a $30 \%$ reduction in diaphragm mass. When corrected for actual mass of the diaphragm, however, twitch characteristics and force generation during the force-frequency protocol were unaltered, indicating that no intrinsic impairment of the contractile machinery occurred. Two other studies reported the effects of the fluorinated steroid triamcinolone $(7,8)$. In the study of Wilcox et al. (7), triamcinolone was administered to hamsters in a dose of $3 \mathrm{mg} / \mathrm{kg}$ per d i.m. during $21 \mathrm{~d}$. Viires et al. (8) investigated rats $8 \mathrm{~d}$ after a bolus administration of $12 \mathrm{mg} / \mathrm{kg}$ triamcinolone i.m. Similarly to our study, in these studies a $\pm 30 \%$ reduction in diaphragm mass due to type IIb fiber atrophy was shown, with a relative predominance of fatigue resistant muscle fibers. This was reflected by an increase in $1 / 2 \mathrm{RT}$, prolongation of TPT, and reduced fatigability of the diaphragm (7). A similar pattern of changes was noticed in the triamcinolone-treated rats in the present study. In the abovementioned studies massive doses of fluorinated steroids were administered in contrast to the present study. Consequently, acute atrophy and rhabdomyolysis might have been induced in these studies. This has also been observed in patients treated acutely with massive doses of corticosteroids (26-30). Their pattern of acute generalized muscle atrophy and weakness, however, is distinctly different from the
Table IV. Diaphragm Fiber Type Distribution

\begin{tabular}{lccc}
\hline \multicolumn{1}{c}{ Treatment } & Type I & Type IIa & Type IIb \\
\hline & & $\%$ & \\
Control & $40(3)$ & $30(3)$ & $30(4)$ \\
$\begin{array}{l}\text { Prednisolone } \\
1.25 \mathrm{mg} / \mathrm{kg}\end{array}$ & $39(3)$ & $28(3)$ & $32(3)$ \\
$\quad 5 \mathrm{mg} / \mathrm{kg}$ & $40(2)$ & $28(2)$ & $32(3)$ \\
$\begin{array}{l}\text { Triamcinolone } \\
\quad 1 \mathrm{mg} / \mathrm{kg}\end{array}$ & $40(6)$ & $26(6)$ & $35(6)$ \\
\hline
\end{tabular}

Mean \pm SD

clinical pattern observed during chronic steroid myopathy. The latter occurs after prolonged administration of steroids and is characterized by the insidious onset of muscle weakness predominantly localized in the proximal extremities (31).

The extent to which the diaphragm is affected by prednisolone, a nonfluorinated steroid that is frequently used in clinical practice, has not yet been studied. Proximal limb muscle weakness does occur with this drug $(3,31)$, and generalized or selective muscle fiber atrophy is less frequently associated with prednisolone treatment (31). A clear explanation for this difference in response to steroids is not available nor is the apparent discrepancy between the antiinflammatory effects and the muscle structure effects well understood. Fluorination of the steroid skeleton enhances all biological activities. The exact mechanism, however, by which fluorinated steroids cause extensive muscle damage compared with nonfluorinated steroids is not known. A difference in binding of triamcinolone, dexamethasone, and cortisol to cytoplasmatic proteins may contribute (32).

Regardless of the exact mechanism, the histological and physiological changes appear to be in line with one another. In the triamcinolone-treated animals the relative contribution of slow (type I) fibers in the diaphragm is increased because of selective atrophy of type IIb fibers. This resulted in prolongation of $1 / 2 \mathrm{RT}$ and an upward shift of the force-frequency curve at low frequencies. The relationship between the myogenic changes found in the prednisolone-treated animals and the physiological abnormalities is unclear. Glycogen storage may increase while its breakdown may decrease due to prednisolone. This might increase the susceptibility to fatigue during the various stimulations.

Although morphometric analysis in the present study was performed using a standardized procedure, fiber dimensions depend upon the degree of shortening when the diaphragm is excised. Indeed, an excised diaphragm bundle will assume its equilibrium length, which may imply a shortening up to $\sim 40 \%$ in dogs, associated with loss of passive tension present in vivo (33). Since passive tensions were similar in the present study, shortening to equilibrium length was likely to be similar as well. The preponderance of connective tissue in the TR

Figure 5. (Top, left and right) Representative ATPase staining at $\mathrm{pH} 4.3$ (25×) from control (left) and LD prednisolone group diaphragm (right). Type I (*), IIa (*), and IIb ( $(*)$ fibers are indicated. (Bottom left) Representative hematoxylin and eosin (25×) from HD prednisolone group diaphragm. Note increased amount of connective tissue $(C T)$ between fibers, scattered necrotic fibers $(\star)$, and excess of nuclei (arrows). (Bottom, right) Representative ATPase staining at pH 4.3 (25x) from triamcinolone group diaphragm. Fiber types I (*), IIa (*), and IIb (*) are indicated. Note reduction in dimensions of type IIb fibers compared with the top panels. 

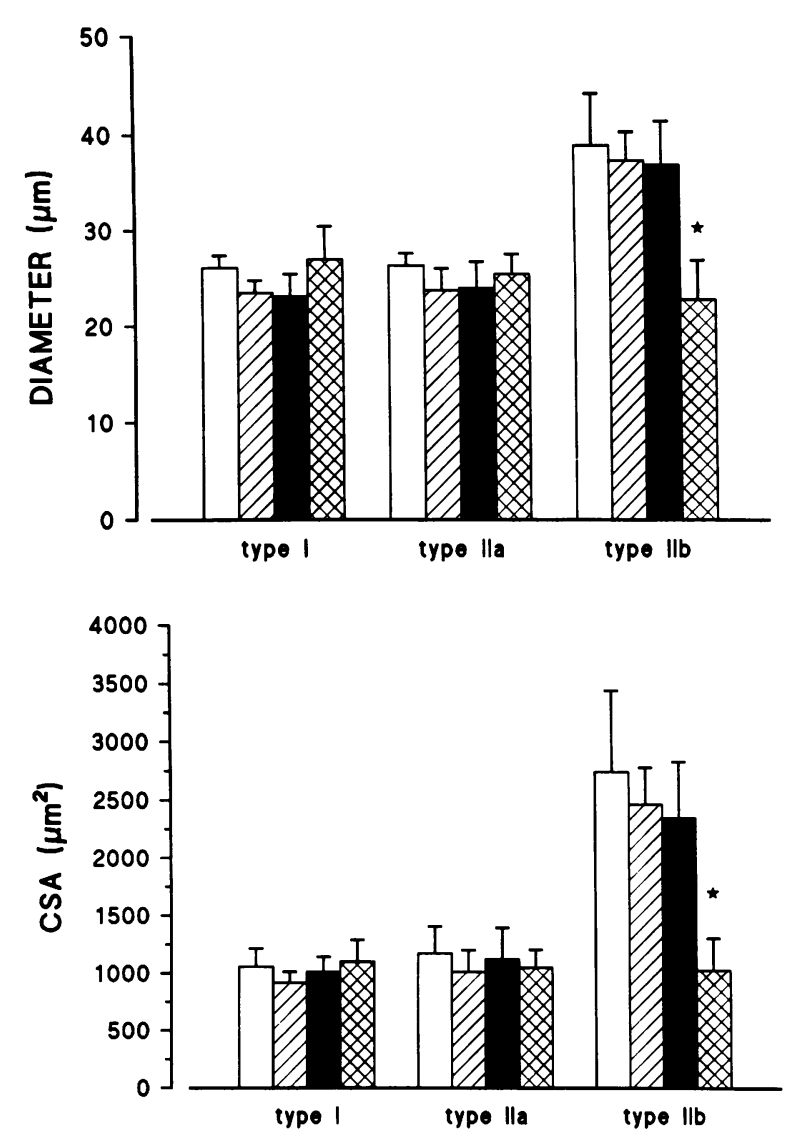

Figure 6. (Top) Fiber diameters in the four groups. (Bottom) Fiber CSA. ${ }^{*} P<0.001$ compared with all other groups. Open bars, control; hatched bars, LD prednisolone; solid bars, HD prednisolone; crosshatched bars, triamcinolone.

group would only affect excised sarcomere length differently from the other groups to the extent that it changes passive tension. As this was not the case, the selective type IIb fiber atrophy in the TR diaphragms cannot be related to bundle shortening alone.

In several studies a pair-fed control group was included (6, $8,11,12$ ) to distinguish the effects of steroids from the effects of malnutrition and weight loss. Such pair-fed control groups were not used in other investigations $(7,9,10)$ nor in the present study. In the study by Moore et al. (6) no significant differences were found in diaphragm mass and contractile properties between a pair-fed and an ad libitum-fed control group. Furthermore, studies on malnutrition in rats have shown that CSA of type I, IIa, and IIb fibers decreased significantly, with the greatest effect on type IIb fibers (34). In another study in hamsters, CSA of type Ila and IIb was reduced to 76 and $77 \%$ compared with normal, whereas type I CSA was unaffected (35). These effects are clearly different from the findings in both prednisolone- and triamcinolone-treated animals in the present study. In prednisolone-treated animals no body weight loss or atrophy of diaphragm fibers was found. In the triamcinolone animals atrophy was strictly limited to type IIb fibers. The latter observation may be of clinical relevance if similar changes were to be present in patients. The absence of type IIa fiber atrophy would then allow to distinguish effects of triamcinolone from malnutrition.
The reduction in respiratory muscle mass in the TR group may be expected to reduce respiratory muscle strength. If respiratory muscle strength falls below $\sim 30 \%$ of normal, respiratory failure is expected to ensue (36). Since obduction in two animals of the TR group revealed no gross macroscopic abnormalities, we assume that respiratory failure was the cause of death in the majority of these animals. Nacházel and Palecek (37) studied the effects of $60 \mathrm{mg} / \mathrm{kg}$ hydrocortisone i.m. during $8 \mathrm{~d}$ on the breathing pattern in normal rats. Diaphragm mass decreased by $44 \%$. Breathing pattern and arterial carbon dioxide tension $\left(\mathrm{PaCO}_{2}\right)$ at rest were unaltered, but the response to an increased ventilatory load was diminished in the steroid-treated animals. Further studies are required to investigate the occurrence of respiratory failure during triamcinolone treatment in rats.

In previous studies the doses of steroids administered were high compared with current use in clinical practice. In the present study prednisolone was administered in doses of 1.25 and 5 $\mathrm{mg} / \mathrm{kg}$ per d. Assuming an absorption of $60 \%$ (6) after intramuscular injection, these doses are equivalent in a $60-\mathrm{kg}$ human to 45 and $180 \mathrm{mg} / \mathrm{d}$, respectively. The lower dose is not uncommon in the treatment of patients with asthma and COPD, and even more so in patients with interstitial lung disease. Although the effects of prednisolone are subtle, the present study concentrates on normal rats. It may be speculated that the effects of steroids on already impaired diaphragmatic function as in patients with COPD might be more pronounced, although no direct evidence for this statement is presently available.

In conclusion, the present study shows that triamcinolone and prednisolone have different effects on morphology and contractile properties of the rat diaphragm. Fluorinated steroids such as triamcinolone caused severe muscle wasting due to selective type IIb fiber atrophy, resulting in markedly reduced respiratory muscle strength. Prednisolone in four times higher doses caused a tendency towards lower tetanic tensions and increased fatigability of diaphragmatic muscle bundles, with distinct alterations in muscle histology.

\section{Acknowledgments}

The authors thank Ms. N. Buts for expert technical assistance.

Supported by grants from the Dutch Asthma Foundation and Fonds voor Geneeskundig Wetenschappelijk Onderzoek.

\section{References}

1. Williams, R. S. 1959. Triamcinolone myopathy. Lancet. 1:698-701.

2. Golding, D. N., S. M. Murray, G. W. Pearch, and M. Thompson. 1961. Corticosteroid myopathy. Ann. Phys. Med. 5:171-176.

3. Faludi, G., J. Gotlieb, and J. Meyers. 1966. Factors influencing the development of steroid-induced myopathies. Ann. NY Acad. Sci. 138:61-72.

4. Afifi, A. K., R. A. Bergman, and J. C. Harvey. 1968. Steroid myopathy. Clinical, histologic and cytologic observations. John Hopkins Med. J. 123:158174.

5. Askari, A., P. J. Vignos, and R. W. Moskowitz. 1976. Steroid myopathy in connective tissue disease. Am. J. Med. 61:485-492.

6. Moore, B. J., M. J. Miller, H. A. Feldman, and M. B. Reid. 1989. Diaphragm atrophy and weakness in cortisone-treated rats. J. Appl. Physiol. 67:2420-2426.

7. Wilcox, P. G., J. M. Hards, K. Bockhold, B. Bressler, and R. L. Pardy. 1989. Pathologic changes and contractile properties of the diaphragm in corticosteroid myopathy in hamsters: comparison to peripheral muscle. Am. J. Respir. Cell. Mol. Biol. 1:191-199.

8. Viires, N., D. Pavlovic, R. Pariente, and M. Aubier. 1990. Effects of steroids on diaphragmatic function in rats. Am. Rev. Respir. Dis. 124:34-38. 
9. Ferguson, G. T., C. G. Irvin, and R. M. Cherniack. 1990. Effects of corticosteroids on diaphragm function and biochemistry in the rabbit. Am. Rev. Respir. Dis. 141:156-163.

10. Ferguson, G. T., C. G. Irvin, and R. M. Cherniack. 1990. Effects of corticosteroids on respiratory muscle histopathology. Am. Rev. Respir. Dis. 142:10471052.

11. Sasson, L., A. Tarasiuk, D. Heimer, and H. Bark. 1991. Effect of dexamethasone on diaphragmatic and soleus muscle morphology and fatigability. Respir. Physiol. 85:15-28.

12. Lewis, M. I., S. A. Monn, and G. C. Sieck. 1992. Effect of corticosteroids on diaphragm fatigue, SDH activity, and muscle fiber size. J. Appl. Physiol. 72:293-301.

13. Wang, Y., T. Zintel, A. Vasques, and C. G. Gallagher. 1991. Corticosteroid therapy and respiratory muscle function in humans. Am. Rev. Respir. Dis. 144:108-112.

14. Janssens, S., and M. Decramer. 1989. Corticosteroid-induced myopathy and the respiratory muscles. Report of two cases. Chest. 95:1160-1162.

15. Decramer, M., and K. J. Stas. 1992. Corticosteroid-induced myopathy involving respiratory muscles in patients with COPD or asthma. Am. Rev. Respir. Dis. 146:800-802.

16. Dekhuijzen, P. N. R., and M. Decramer. 1992. Steroid-induced myopathy and its significance to respiratory disease: a known disease rediscovered. Eur. Respir. J. 5:997-1003.

17. Metzger, J. M., K. B. Scheidt, and R. H. Fitts. 1985. Histochemical and physiological characteristics of the rat diaphragm. J. Appl. Physiol. 58:10851091.

18. McCully, K. K., and J. A. Faulkner. 1983. Length-tension relationship of mammalian diaphragm muscles. J. Appl. Physiol. 54:1681-1686.

19. Reid, M. B., and M. J. Miller. 1989. Theophylline does not increase maximal tetanic force or diaphragm endurance in vitro. J. Appl. Physiol. 67:1655-1661.

20. Burke, R. E., D. N. Levine, and F. E. Zajac. 1971. Mammalian motor units: physiological-histochemical correlation in three types in cat gastrocnemius. Science (Wash. DC). 174:709-712.

21. Dubowitz, V. 1985. Muscle Biopsy. A Practical Approach. Bailliere Tindall, London, U.K.

22. Norusis, M. J. 1988. SPSS/PC+ Base Manual. SPSS Inc., Chicago, IL.
23. Segal, S. S., and J. A. Faulkner. 1985. Temperature-dependent physiological stability of rat skeletal muscle in vitro. Am. J. Physiol. 248:C265-C270.

24. Taylor, R. G., R. T. Abresch, J. S. Lieberman, W. M. Fowler, and M. M. Portwood. 1984. Effect of pentobarbital on contractility of mouse skeletal muscle. Exp. Neurol. 83:254-263.

25. Warner, D. O., M. J. Joyner, and K. Rehder. 1992. Electrical activation of expiratory muscles increases with time in pentobarbital-anesthetized dogs. $J$. Appl. Physiol. 72:2285-2291.

26. MacFarlane, I. A., and F. D. Rosenthal. 1977. Severe myopathy after status asthmaticus. Lancet. ii:615.

27. Marle van, W., and K. L. Woods. 1980. Acute hydrocortisone myopathy. Br. Med. J. 281:271-272.

28. Knox, A. J., B. Mascie-Taylor, and M. F. Muers. 1986. Acute hydrocortisone myopathy in acute severe asthma. Thorax. 41:411-412.

29. Williams, T. J., R. E. O'Hehir, D. Czuruy, M. Horne, and G. Bowes. 1988. Acute myopathy in severe acute asthma treated with intravenously administered corticosteroids. Am. Rev. Respir. Dis. 137:460-463.

30. Shee, C. D. 1990. Risk factors for hydrocortisone myopathy in acute severe asthma. Respir. Med. 84:229-233.

31. Ruff, R. L. 1986. Endocrine myopathies. In Myology. A. G. Engel and B. Q. Banker, editors. McGraw-Hill Book Company, New York. 1871-1906.

32. Mayer, M., and F. Rosen. 1977. Interaction of glucocorticoids and androgens with skeletal muscle. Metab. Clin. Exp. 26:937-945.

33. Tao, H.-Y., and G. A. Farkas. 1992. Predictability of ventilatory muscle optimal length based on excised dimensions. J. Appl. Physiol. 72:2024-2028.

34. Lewis, M. I., G. C. Sieck, M. Fournier, and M. J. Belman. 1986. Effect of nutritional deprivation on diaphragm contractility and muscle fiber size. J. Appl. Physiol. 60:596-603.

35. Kelsen, S. G., M. Ference, and S. Kapoor. 1985. Effects of prolonged undernutrition on structure and function of the diaphragm. J. Appl. Physiol. 58:1354-1359.

36. Braun, N. M. T., N. S. Arora, and D. F. Rochester. 1983. Respiratory muscle and pulmonary function in polymyositis and other proximal myopathies. Thorax. 38:616-623.

37. Nacházel, J., and F. Palecek. 1993. Respiration in anesthetized rats after phrenicotomy and hydrocortisone treatment. Eur. Respir. J. 6:547-551. 